and that research on "less harmful" varieties of tobacco should be stopped since there is no such thing as unharmful tobacco. The delay in funding projects from the tobacco research and information fund and the closure of the Bureau for Action on Smoking Prevention raise serious questions about the competence, motivation, and judgment of directorate general V of the European Commission.

The 1992 reforms did not address the fundamental issue: abolition of tobacco subsidies altogether. They had some limited benefits, including the abolition of export subsidies and intervention support, although it remains to be seen what long term effect the ending of export subsidies will have. Many of these exports are of high tar tobacco to less developed countries. The limiting of overall production is a small step forward, as is the reduction in overall expenditure. Nevertheless, the estimate for 1996 expenditure exceeds the 1995 figure, and overall expenditure is unlikely to fall much below $1000 \mathrm{~m}$ ecu. This is still a huge sum for a crop whose commercial value is one tenth of that.

The new data on the commercial value of the crop clearly show that the European Union's tobacco subsidies are economic nonsense. They remove the last line of defence of the policy, that of income support for farmers. Tobacco subsidies have proved phenomenally expensive, have failed to adapt production to demand, have failed to reduce imports, are in direct conflict with health policy, and are an economically inefficient way of providing income for farmers. We agree with the Court of Auditors' conclusion that it would be better to provide direct income support to farmers not to grow tobacco. Tobacco subsidies are now indefensible.

Funding: None

Conflict of interest: $\mathrm{LJ}$ was former director of BASP.

1 Joossens L, Raw M. Tobacco and the European common agricultural policy. British foumal of Addiction 1991;86:1191-1202.

2 Council Regulation (EEC) No 2075/92 of 30 June 1992 on the common organisation of the market in raw tobacco. Official fournal of the European Communities. 1992; I 215:70ff.

3 Court of Auditors. Special report No 8/93 concerning the Common organisation of the market in raw tobacco together with the commission's replies. Official foumal of the European Communities 1994;C65 volume 37, 2 March.

4 Commission of the European Communities. Report from the Commission to the Council on the allocation of quotas for certain varieties of tobacco in Greece. Com (93) 71 final, $19 \mathrm{Feb} 1993$.

5 Commission Regulation (EEC) No 3478/92 of 1 December 1992. laying down detailed rules for the application of the premium system for raw tobacco. detailed rules for the application of the premium system 6 Slama K. Tobacco and health. New York: Plenum Press, 1995.

(Accepted 12 March 1996)

\title{
Over the Counter Drugs
}

\section{The future for self medication}

\author{
Colin Bradley, Alison Blenkinsopp
}

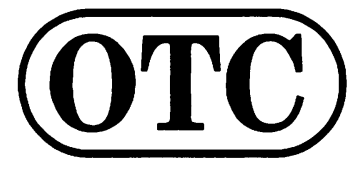

This is the last of four articles examining the implications of the availability and use of nonprescription medicines for health services in Britain and elsewhere

Medical School, University of Birmingham, Birmingham B15 2T

Colin Bradley, senior lecturer in general practice

\section{Department of Pharmacy} Policy and Practice, University of Keele, Keele, Staffordshire ST5 5BG

Alison Blenkinsopp, director

of education and research

Correspondence to: Dr Bradley.

$B M F$ 1996;312:835-7
The increasing trend towards deregulation of more medicines to over the counter status has implications for the primary health care team as well as for consumers and patients. Better information for patients could improve the safety of over the counter medicines, but better systems need to be devised for reporting adverse reactions. "Collaborative care" could bring financial benefits. Doctors, nurses, and pharmacists need to discuss how they will respond to self medication practices, and ways of rewarding pharmacists for advising patients need to be found. Improved communication between doctors and pharmacists and the involvement of nurses could bring health care professionals into a new and more constructive interaction with each other and with the patient-or the changes required could split the professions as they each try to keep control of medicines.

Predicting the future is always risky, but current trends and the stated intentions of policy makers and stakeholders are often helpful. As we argued in the first article in this series, the factors promoting greater availability and use of over the counter medicines far outweigh the inhibitors. ${ }^{1}$ The uncertainty is therefore how far this trend will go and how health care professionals and consumers will respond.

\section{Current trends}

More drugs were changed from prescription only medicines (POM) to pharmacy $(P)$ medicines in the past two years than over the previous decade. ${ }^{1}$ Furthermore, the range now encompasses drugs which have, on prescription, been used for potentially more serious and longer term conditions. ${ }^{2}$ Some of the more recently deregulated medicines $\left(\mathrm{H}_{2}\right.$ antagonists, for example) may not seem to doctors to be natural choices for over the counter use. However, formulations, dosages, and licensed indications for drugs that become available over the counter are not necessarily the same as those which pertain to its use as a prescription only preparation.

The explicit policy in medicines licensing and relicensing in Britain and throughout the developed world is that a drug should be made freely available to patients unless a case can be made for its availability being restricted. ${ }^{3}$ The main ground for restrictions is safety. But safety is not simply an intrinsic feature of the drug-it can arguably be achieved by providing better information to the patient. In Australia it was thought that $\beta$ agonists could safely be supplied over the counter if pharmacists were required to provide additional information. ${ }^{4}$ Similarly, those arguing for oral contraceptives and emergency contraception being available over the counter predicate their argument on the provision of better information to the patient. ${ }^{56}$ The Medicines Control Agency now puts great emphasis on the provision of information for patients in its assessment of applications for drugs to be switched from prescription only to pharmacy status. ${ }^{3}$

\section{Future trends}

If safety concerns can generally be met by providing adequate information, this opens the way to an even wider range of drugs becoming available over the counter. And there are pressures to extend the range considerably. One influential force for change has been the Royal Pharmaceutical Society, whose list of drugs suggested in 1991 for switching to pharmacy status has clearly influenced which drugs have been switched so far. " Still included on the society's "hit list" are antibiotic eye drops and topical creams and oral antifungal agents. Since many of these drugs are reasonably safe in normal use (and some, such as 


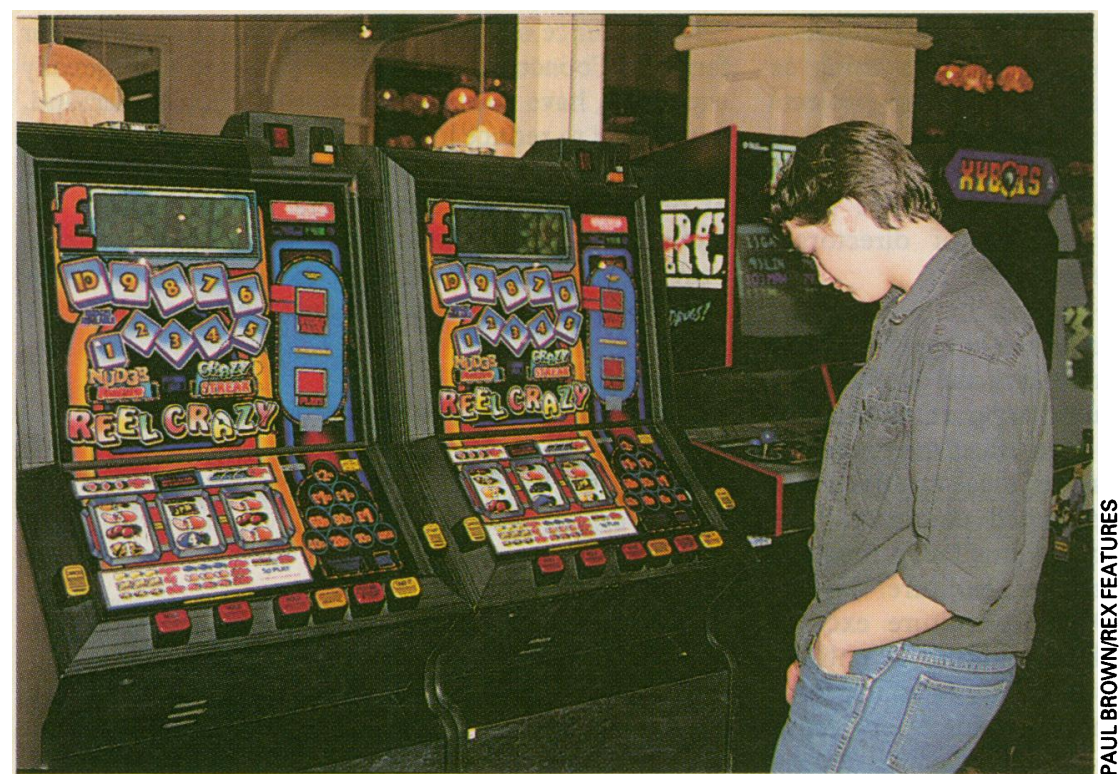

As patients gain more and more access to the means to treat their illnesses, who can best advise them? ing confidentiality of patient data and incompatibility of computer systems will need to be ironed out.

Because of their continuous and regular contact with much of the population, general practitioners have a particularly vital role in ensuring that medicines continue to be used safely even when they are more widely available without a consultation taking place. To fulfil this role they must become more acceptable to patients as advisers on self medication. At present, consumers of over the counter medicines find pharmacists a more acceptable source of advice. Some patients see a recommendation by a general practitioner to use an over the counter medicine as an attempt to fob them off. ${ }^{8}$ Patients also recognise that many general practitioners are less than enthusiastic about self medication; hence they are reluctant to discuss their self medication practices with their general practitioner. These attitudes will have to be changed. Doctors cannot ignore or discourage prior self medication, and knowledge of such medication is essential, if only to check that the patient has not already tried the medicine that is about to be prescribed. It is also obviously important to guard against drug interaction between over the counter and prescribed medicines.

The patient empowerment that flows from deregulation can be seen as a good thing. Doctors who encourage and support responsible self medication will be seen by their patients as a more acceptable source of independent advice. The role of the doctor will then evolve to one of a collaborator with patients in the management of their health problems rather than an exclusive controller of access to medicines. The alternative approach of fighting to retain control over access to medicines will mean that, as patients gain more and more access to the means to treat their own illnesses, doctors will be rejected as a source of help and advice. Patients will, naturally, continue to need access to special information to deal with health problems that are often complex, but they may turn to other sources such as other health professionals who have more "liberal" attitudes, or, increasingly, to written and electronic sources of information. would need to take a greater share of the responsibility for their care and would have to pay for their drugs, which would be purchased over the counter. Many of the benefits of collaborative care could be achieved more simply by introducing "repeat dispensing" by pharmacists: provision for the doctor to specify on a prescription how often it is to be repeated before medical review (this currently exists only for private prescriptions) and by better communication between general practitioners and pharmacists.

The appeal of "collaborative care" to those who fund health care is obvious. It would allow some of the costs of repeat prescriptions to be shifted at least partially to patients-perhaps a more politically acceptable approach than a copayment system or a further hike in prescription charges.

\section{Implications for doctors}

If the scope of self medication widens as predicted, doctors, pharmacists, and other health professionals will need to respond in a more active and constructive way than they have to date. Greater vigilance for adverse reactions is needed, and the reporting system should be widened to include pharmacists. Doctors must improve on their current record of reporting adverse drug reactions using the yellow card system. Doctors and pharmacists need to clarify their attitudes towards deregulation and try to reach a consensus about how their shared goal of the safe and effective use of medicines can be achieved. This will require more communication between them; electronic forms of communications should help, but difficulties regard-

\section{Implications for pharmacists}

For pharmacists the widening scope for self medication brings different challenges. It might seem to creased sales, but in the longer term it could reduce income through the loss of dispensing fees and the associated professional allowance and could even threaten the viability of some pharmacies. More importantly, however, the professional input into the patient's choice of medicine could be lost unless a mechanism can be found for rewarding professional advice rather than just the dispensing of medicines. If doctors do not rise to the challenges of greater self medication, patients may turn to pharmacists instead. If pharmacists were to exploit this opportunity to extend their role in direct opposition to doctors the already wary relations between the two professions could deteriorate further. This is unlikely to benefit patients. operation between doctors and pharmacists to ensure that patients get the best possible advice, both on macists. Evidence that this is happening comes from the increasing number of initiatives in which doctors and pharmacists are forging links to improve patients' use of medicines. These positive developments need to be strongly encouraged and developed. Current obstacles to greater cooperation include the separate locations of doctors and pharmacists (in most cases) create the possibility of greater profits through in-

A more optimistic scenario envisages greater codiagnosis from doctors and on medication from phar- 
and the regulations which tie the pharmacist to the shop during opening hours. Freeing pharmacists to participate in more joint activities in undergraduate medical teaching, vocational training for general practitioners, and continuing professional development would help both professions.

Better communication is also vital-not just about individual prescriptions for individual patients but about policy making in both practices and pharmacies. Practice prescribing policies should take account of pharmacies' policies on the recommendation of over the counter products, and vice versa, so that patients receive consistent messages. Mechanisms similar to those used in the development of general practice formularies 9 should be applied to formularies of over the counter drugs, with the proviso that pharmacy customers have the right to choose drugs other than those in the formulary.

\section{Nurses and over the counter medicines}

The extension of the nursing role and, in particular, the development of specialist nursing functions (for example, in health promotion and management of chronic diseases) also have potential to influence consumer choice of over the counter drugs. Nurse prescribing is now being piloted in various locations. The potential upward effect of nurse prescribing on practices' prescribing costs might be decreased by nurses becoming more involved in recommending medicines available over the counter. Many practice nurses are already advising patients about over the counter solutions to minor health problems, and as the range of products increases, nurses are likely to become involved in recommending them sooner and across a wider range of drugs than they are going to be allowed to prescribe for. Training is needed for nurses to fulfil this new role, which is as likely to be thrust on them as to be sought by them; ideally, they ought to be brought into the joint training proposed above for doctors and pharmacists. Nurses also need to establish lines of communication with community pharmacists, meeting with them to exchange ideas and problems and develop policies. They should be brought into new, broader mechanisms for reporting adverse drug reactions and into practice and pharmacy policy making.

\section{The future: dream or nightmare?}

The increasing scope for self medication and its likely consequences can be seen as a shift from "primary care" of both minor and stable health care problems to "self care." Whether this transition occurs smoothly or not depends to a large extent on the attitudes and responses of the primary health care professionals involved, and whether they view this as a positive or negative development. It will also depend on how well informed and equipped the consumers are to take on the burden of self care.

These changes could bring together the health care professionals involved (doctors, nurses, and pharmacists) into a new and more constructive interaction with each other and with the patient-or they could split the professions as they squabble with the patient and with each other for the last vestige of control of medicines, leaving the patient baffled, confused, and vulnerable to the dangers inherent in all medicine taking. Will health professionals rise to the challenge?

\footnotetext{
1 Blenkinsopp A, Bradley C. Patients, society, and the increase in self medication. BMf 1995;312:629-32.

2 Medicines Control Agency. Changing the legal classification of a prescription only medicine for human use. Medicines Control Agency: London, 1992. (MAL medicine for human use.

3 Council Directive for Medicines Classification. Official fournal of the European Community No L 1992 April 30:113/5.

4 Gibson P, Henry D, Francis L, Cruickshank D, Dupen F, Higginbotham N, et al. Association between availability of non-prescription agonist inhalers and undertreatment of asthma. $B M F$ 1993;306:1514-8.

5 OCs o-t-c? Lancet 1993;342:565-6.

6 Drife JO. Déregulating emergency contraception. $B M \Im$ 1993;307:695-6.

7 Society suggests more POM to P changes. Pharm f 1995;254:433.

8 Bradley C. Doctors and patients' views on OTC medication. Prescriber 1995 March 5:75-7.

9 Herxheimer A, Britten N. Formulary for self care. Br $\mathcal{f}$ Gen Pract 1994;44:
} $339-40$.

\section{PAST PRESCRIBING}

\section{An 18th century medical student worries about placebos}

James Beattie, the poet (1735-1803), was professor of moral philosophy at Marischal College, Aberdeen, for the last four decades of the 18th century. He was much loved by his students, who often sought his advice. One of them, Thomas Christie, who had gone to London as a medical student, sent this moral condundrum to Beattie on 31 January 1786 :

"I shall mention to you an opinion delivered to us in the class of Dr Osborne, of which, as it relates to Morals, I should be glad to know your sentiments. He said that in many cases, wherein he knew that no medicine could avail, he nevertheless prescribed a medicine, and that he made it a rule, and recommended it to us, that whenever a Physician is called, he should prescribe something. I do not mean, adds he, that you are to overload the patient's stomach with useless drugs, but you ought to order some simple remedy, something that will do no harm if it does no good. For

“(1) Your Patient expects something of you, and your refusing to give him any thing will damp his expectations, and perhaps give him a desponding view of his case, and these circumstances may often give a fatal turn to the distemper.

"(2) If you prescribe something, however simple, it will have a tendency to revive your patient's spirits, and give him fresh hopes, and it is needless for me to inform you how much the power of the imagination will do in any disease.

"(3) If you prescribe nothing, it is ten to one that your Patient will be dissatisfied with your advice, and entertain doubts of your skill. Perhaps before you have crossed the street, another Physician will be sent for, who will dose the patients with loads of trash, and do more harm in an hour than your scrupulous honesty will do good in a year.

"I confess Dr Osborne's assertion surprised me at first, and I thought it came near to the Jesuitic System. But his arguments are strong, and deserve to be weighed. And there is another thing that occurs to me to strengthen them. In almost all diseases of the body, the mind sympathises . . . and hence pious frauds, intolerable in Theology, are allowable in Medicine." (From a letter in the Beattie collection, Aberdeen University Library Department of Special Collections and Archives, manuscript 30/2/497).

Beattie's comments are not available. Christie was subsequently superintendent of hospitals in Ceylon.

We welcome filler articles of up to 600 words on topics such as $A$ memorable patient, $A$ paper that changed my practice, $M y$ most unfortunate mistake, or any other piece conveying instruction, pathos, or humour. If possible the article should be supplied on a disk. 